\title{
Adaptação transcultural do Questionário sobre Conhecimento de Doenças Sexualmente Transmissíveis para o português brasileiro
}

\author{
Cross-cultural adaptation of Sexually Transmitted Disease \\ Knowledge Questionnaire to Portuguese of Brazil \\ Lisiane Ortiz Teixeira', Vera Lúcia Marques Figueiredo², Raúl Andrés Mendoza-Sassi'
}

\section{RESUMO}

Objetivo: Adaptar o Questionário sobre Conhecimento de Doenças Sexualmente Transmissíveis (STD-KQ) para o português do Brasil. Métodos: $\mathrm{O}$ instrumento foi traduzido para o português e retraduzido para o inglês de forma independente. Seis juízes avaliaram a validade aparente e a validade de conteúdo. A validade de conteúdo foi mensurada pelo Coeficiente de Validade de Conteúdo para cada item (CVCc) e para o questionário como um todo (CVCt). A discussão com a população foi realizada por meio de grupos focais com 15 usuários de centros comunitários e 15 universitários. A dimensão teórica do instrumento foi calculada pelo coeficiente Kappa. Resultados: Um item foi retirado por apresentar baixa validade de conteúdo (CVCc $<0,80)$. Duas questões sobre sífilis foram acrescentadas. Para dimensão teórica, houve substancial concordância entre os juízes. Conclusão: Os resultados

\section{Palavras-chave}

Comparação transcultural, conhecimento, DST, estudos de validação, questionários.

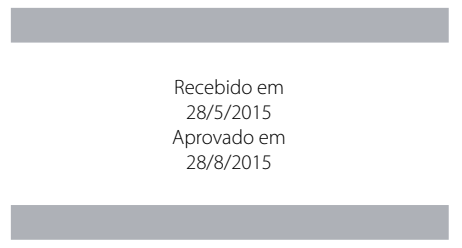

DOI: $10.1590 / 0047-2085000000085$ mostraram que, para clareza da linguagem (CVCt $=0,89)$, pertinência prática $(C V C t=0,92)$ e relevância teórica (CVCt $=0,93)$, os itens propostos parecem adequados para a realização de futuras investigações sobre a validade de constructo e a fidedignidade, os quais produzirão evidências sobre a aplicabilidade desse questionário para avaliação do conhecimento no tema abordado.

\section{ABSTRACT}

Objective: To adapt the Sexually Transmitted Disease Knowledge Questionnaire (STD-KQ) for the Portuguese of Brazil. Methods: The instrument was translated to Portuguese and back-translate to English to independently. Six judges participated of the face validity and content validity. Content validity was measured by the Content Validity Coefficient for each item (CVCc) and for the whole questionnaire (CVCt). The discussion was established with focus groups formed with 15 users of community center and 15 college students. The theoretical dimension of the instrument was calculated using the kappa coefficient. Results: One item was retired because of a lower content validity ( $C V C c<0.80$ ). Two questions about syphilis were appended. For theoretical dimension there was substantial agreement among the judges. Conclusion: These results show that for clarity of language (CVCt $=0.89)$, re-

1 Universidade Federal do Rio Grande (FURG), Programa de Pós-Graduação em Ciências da Saúde.

2 Universidade Católica de Pelotas (UCPel).

Endereço para correspondência: Raúl Andrés Mendoza-Sassi

Programa de Pós-Graduação em Ciências da Saúde (FURG),

Faculdade de Medicina

Rua General Osório, s/n, Centro

96200-400 - Rio Grande, RS, Brasil

Telefone: (53) 3237-4621

E-mail: dmiraul@furg.br 


\section{Keywords}

Cross-cultural comparison, knowledge, STD, validation studies, questionnaires. levance practice $(C V C t=0.92)$ and theoretical relevance $(C V C t=0.93)$, the proposed items seem appropriate for conducting future research on the validity construct and reliability, which will produce evidence about the applicability of this questionnaire for evaluation of knowledge in the research field.

\section{INTRODUÇÃO}

As doenças sexualmente transmissíveis (DST) são um dos problemas de saúde pública mais frequentes no mundo. No Brasil, as estimativas de casos de infecções por transmissão sexual, na população sexualmente ativa para 2014, foram de 937.000 para sífilis, 1.541.800 para gonorreia, 1.967.200 para clamídia, 640.900 para herpes genital e 685.400 para papilomavírus humano (HPV)'.

Medir o conhecimento que uma pessoa detém sobre as DST é essencial para a elaboração de intervenções. A falta desse conhecimento é considerada fundamental para a aquisição de uma DST, segundo as teorias comportamentais, que afiram que o conhecimento do problema de saúde é um determinante modificável para aquisição da doençą2-5.

No entanto, a maioria dos instrumentos avalia o comportamento de risco para aquisição de uma DST, e não o conhecimento sobre esse tema. No site Measurement Instrument Database for the Social Sciences (MIDSS) 6 , que hospeda mais de 500 instrumentos validados, apenas dois instrumentos avaliam o conhecimento a respeito das DST, o General Sexual Knowledge Questionnaire (QSKQ)7 e o Questionário sobre Conhecimento de Doenças Sexualmente Transmissíveis $(\mathrm{STD}-\mathrm{KQ})^{2}$.

O QSKQ avalia o conhecimento sobre anatomia e fisiologia humana, relação sexual, gravidez, contracepção, sexualidade e DST7. O instrumento não é autoaplicável e as questões são abertas. Dos 110 itens, apenas oito avaliam o conhecimento sobre as DST, sendo quatro sobre o vírus da imunodeficiência humana (HIV) e sobre a síndrome da imunodeficiência adquirida (Aids). Na questão sobre como evitar o HIV/Aids, além do uso de preservativo e de agulhas esterilizadas, o instrumento considera como medida preventiva a realização de sexo sem penetração. Segundo o Ministério da Saúde, em algumas situações (cortes abertos na boca, úlceras, machucados, garganta inflamada e doenças nas gengivas), o sexo oral pode contribuir para a aquisição da infecção, por ser uma porta de entrada para o vírus ${ }^{8}$.

Diferente do primeiro instrumento, o STD-KQ foi desenvolvido especificamente para avaliar o conhecimento sobre as DST2 2 . O questionário é formado por 28 itens sobre seis DST (gonorreia, clamídia, herpes genital, HPV, HIV/Aids e hepatite B). Os itens são afirmativos e as respostas são categorizadas em "verdadeiro", "falso" e "não sei", facilitando o preenchimento. Outra vantagem é que é autoaplicado, permitindo seu uso em um grande grupo de pessoas ao mesmo tempo e evitando a possibilidade de inibições ou constrangimentos. $\mathrm{O}$ instrumento apresenta grande aceitação no país de origem (Estados Unidos) ${ }^{9,10}$ e em outros países, sendo utilizado em estudos no Canadá ${ }^{11}$, Portugal ${ }^{12}$, Haiti $^{13}$ e Nigéria ${ }^{14}$. O questionário também foi adaptado para outros idiomas como o francês ${ }^{15}$ e o português de Portugal' ${ }^{16}$.

Além desses dois instrumentos, a Organização Mundial da Saúde desenvolveu o Illustrative Questionnaire for Interview-Surveys with Young People ${ }^{17}$, projetado para jovens púberes que ainda não começaram uma relação estável e apresenta apenas três itens de múltiplas escolhas sobre conhecimento de DST. Além disso, não foram encontrados estudos avaliando suas propriedades psicométricas.

Após analisar os três questionários disponíveis, o STD-KQ surgiu como a melhor alternativa para a finalidade proposta, por ser exclusivamente desenvolvido para medir o conhecimento sobre as DST, por avaliar um maior número de DST e por ser autoaplicado. Além disso, esse é o único questionário a analisar a transmissão vertical de algumas DST, as medidas de proteção e prevenção, como a vacinação, o papanicolau e o exame anti-HIV, além de avaliar mitos ou más informações sobre a transmissão.

Diversos estudos realizados no Brasil avaliaram o conhecimento sobre DST ${ }^{18-22}$. No entanto, a comparação dos resultados fica prejudicada por causa das diferenças metodológicas. Entre essas diferenças está a falta de consenso sobre a forma de avaliar o desfecho. Alguns estudos avaliam o conhecimento por meio de um único valor de percentagem ${ }^{20}$ e outros avaliam o conhecimento individualmente para cada item do instrumento ou para tópicos específicos (prevenção, tratamento, transmissão) 18,19,21. O desfecho ainda pode ser apresentado de forma qualitativa (ótimo, bom, insuficiente $)^{22}$ e as perguntas podem ser abertas ${ }^{22}$ ou fechadas ${ }^{20}$. Nesse contexto, e para facilitar futuras investigações nessa área, este estudo teve como objetivo adaptar o STD-KQ para o português do Brasil, permitindo, assim, comparar os resultados de estudos realizados no Brasil e no exterior.

\section{MÉTODOS}

Foi utilizado delineamento transversal. A coleta de dados ocorreu de julho de 2014 a março de 2015, com a prévia autorização do autor correspondente do questionário original. Após buscas nas bases científicas Lilacs e PubMed, no Portal Periódicos da Capes, na Biblioteca Digital Brasileira de Teses e Dissertações e o contato com o autor da versão original, não foram encontrados no Brasil artigos que tenham realizado a adaptação desse instrumento. Este estudo foi aprovado 
pelo Comitê de Ética da Universidade Federal do Rio Grande (CEPAS-FURG).

\section{Descrição do Instrumento}

A versão original da escala STD-KQ - Sexually Transmitted Disease Knowledge Questionnaire em inglês - é escrita em inglês, autoaplicada e constituída por 27 itens. O objetivo é avaliar o conhecimento sobre as DST e foi elaborada com base nas cinco DST mais prevalentes nos Estados Unidos. Os estudantes universitários foram a população em que a escala foi validada. As respostas são categorizadas em "verdadeiro", "falso" e "não sei". Calcula-se o resultado final pelo somatório das respostas corretas, sendo o mínimo 0 e o máximo $28^{2}$.

A respeito das propriedades psicométricas do questionário original, a consistência interna foi de 0,86 , o teste-reteste apresentou correlação linear de $r=0,82$, e o coeficiente de Pearson para a validade convergente com o HIV-KQ-18 ${ }^{23}$ foi de $0,64(p<0,01)$. A sensibilidade a mudanças entre o resultado do pré-teste e o do pós-teste entre o grupo controle e o grupo intervenção foi significativa. Esse instrumento avalia quatro (80\%) das cinco DST mais prevalentes no Brasil. A DST sífilis não é abordada nesse instrumento, visto não ser epidemiologicamente relevante nos Estados Unidos. Contudo, durante o processo de adaptação transcultural, essa DST poderá ser acrescentada, a fim de contemplar a situação epidemiológica brasileira.

\section{Adaptação transcultural}

Foi utilizada a metodologia descrita por Reichenheim ${ }^{24}$, que aborda a equivalência conceitual e de itens, a equivalência semântica e a equivalência operacional.

A equivalência conceitual foi avaliada por meio de uma revisão bibliográfica dos artigos a respeito dos grupos participantes e da cultura do STD-KQ. Os autores desse estudo analisaram o instrumento e discutiram sobre a sua adaptação.

A equivalência semântica foi integrada por duas traduções independentes do inglês para o português (T1 e T2) e duas retraduções também independentes para o inglês (R1 e R2). As traduções foram efetuadas por dois bacharéis em Ciências Biológicas certificados como Independent user vantange pelo Test of English as a Foreign Language (TOEFL) e que executam pesquisas a respeito das DST há mais de cinco anos. As retraduções foram realizadas por dois brasileiros licenciados em letras português/inglês, certificados como proficientes pelo TOEFL e pelo Cambridge Certificate of Advanced English. Um dos pesquisadores do estudo, certificado como proficiente pelo TOEFL, efetuou a comparação entre as retraduções e o instrumento original. Após a confirmação da equivalência semântica, foi formulada uma versão de consenso de T1 e T2 pelos tradutores. O número de traduções e retraduções são os sugeridos por Reichenheim²4.

Para avaliar a equivalência operacional, os autores do presente estudo avaliaram o formato das questões, as orientações de preenchimento do instrumento e o modo de aplicação.

A apreciação da equivalência pelos especialistas foi realizada por meio da validade aparente e da validade de conteúdo. Participaram dessas etapas seis juízes, cinco deles médicos (quatro infectologistas e um ginecologista e obstetra) e uma enfermeira do consultório de aconselhamento sobre HIV/Aids e outras DST. O critério para a escolha de seis juízes foi definido pelos autores do estudo, levando em consideração que os artigos consultados que utilizam essa metodologia escolhem entre três ${ }^{25}$ e sete ${ }^{26}$ juízes. Os juízes, além de atuar na assistência, também ministram aulas sobre as DST na universidade na qual este estudo foi realizado.

Durante a validade aparente, cada item do questionário foi classificado pelos juízes como adequado ou inadequado para avaliar o conhecimento da população brasileira sobre as DST. A concordância entre os juízes foi mensurada pelo método de porcentagem de concordância ${ }^{27}$. O ponto de corte estabelecido foi de $70 \%$. Itens com valores menores que o ponto de corte foram alterados segundo as recomendações dos juízes.

A validade de conteúdo foi mensurada pelos mesmos seis juízes que avaliaram a validade aparente. Utilizando uma escala do tipo Likert, os juízes atribuíram notas de 1 (não adequado) a 5 (totalmente adequado) para cada item do questionário em relação a três critérios: clareza de linguagem, pertinência prática e relevância teórica. Os juízes, utilizando a mesma escala, ainda analisaram todo o questionário em relação a amplitude e equilíbrio. Em relação a amplitude, os juízes analisaram se o questionário avaliava todos os aspectos do conhecimento sobre as DST que uma pessoa necessita ter. Caso os juízes acreditassem que eram necessários mais itens, eles deveriam elaborar sugestões de novos itens. A respeito do equilíbrio, os juízes avaliaram o grau de dificuldade do questionário. O questionário deve ter número reduzido de itens fáceis ou difíceis, apresentando grau de conhecimento mediano. A concordância entre os juízes foi calculada pelo Coeficiente de Validade de Conteúdo (CVC) para cada item do instrumento (CVCc) e para o instrumento como um todo (CVCt), considerando o número de juízes e a média das respostas deles ${ }^{28}$. O ponto de corte adotado foi de $C V C \geq 0,80^{28}$. Itens com valores menores que o ponto de corte foram retirados. Quando um item apresentou valor menor que o ponto de corte apenas para a clareza de linguagem, assim como na validação aparente, o item foi alterado segundo as recomendações dos juízes. Essas alterações foram realizadas por um dos autores do estudo. Após as modificações, os juízes não reavaliaram o instrumento. Um especialista independente (médico ginecologista e obstetra), que não tinha participado do estudo até esse momento, verificou se as alterações foram realizadas de acordo com as recomendações dos juízes. Houve cegamento em relação à identidade dos juízes tanto para o autor que realizou as modificações 
quanto para o especialista independente. Ao término dessas etapas, foi elaborada a segunda versão do questionário.

Os juízes avaliaram ainda a dimensão teórica de cada item, classificando-os em "Conhecimento Geral sobre DST" ou "Formas de Transmissão e Prevenção". A concordância entre os juízes foi calculada pelo coeficiente Kappa. Para interpretação desse coeficiente, foi utilizado o seguinte critério: $<0$ = sem concordância; 0-0,19 = pouca concordância; 0,20-0,39 = concordância fraca; 0,40-0,59 = concordância moderada; $0,60-0,79=$ concordância substancial; $0,80-1,00=$ concordância quase perfeita ${ }^{29}$.

A apreciação da equivalência da segunda versão pela população brasileira foi realizada por meio de aplicações dialogadas em grupos focais ${ }^{30,31}$. Participaram dessa etapa 15 estudantes universitários e 15 usuários de quatro centros comunitários (associações de bairro). O número de participantes nos grupos focais foi estabelecido pelos autores, assumindo que esse número seria suficiente e adequado para proceder com a avaliação qualitativa do instrumento. A seleção foi de conveniência, mantendo distribuição homogênea em relação ao sexo, à idade e ao curso para os universitários e ao sexo e à idade para os usuários dos centros comunitários. Um dos pesquisadores do estudo recrutou individualmente os estudantes em diversos ambientes universitários. Os usuários dos centros comunitários foram recrutados individualmente nos centros comunitários. Nesse momento, o pesquisador explicou o estudo para os sujeitos da pesquisa e, caso o participante concordasse verbalmente em participar do estudo, ele era direcionado para uma sala exclusiva dentro da universidade ou dentro dos centros comunitários para proceder às entrevistas. Foram formados dez grupos focais, cada um com três participantes e um dos autores. Para os universitários, cada um dos três integrantes eram de cursos diferentes. Em seguida, os participantes assinaram o termo de consentimento livre e esclarecido e preencheram um questionário com dados demográficos, a fim de obter informações para caracterizar a amostra. Informações sobre as práticas e comportamentos sexuais dos participantes não foram coletadas. O pesquisador do estudo executou primeiramente a leitura do enunciado introdutório do instrumento, discutindo com o grupo formas de torná-lo mais compreensível. Em seguida, cada um dos itens foi discutido em relação a sua clareza e a sua compreensão. Todas as sugestões e críticas foram devidamente anotadas e posteriormente apresentadas para o restante do grupo de pesquisa. Não houve delimitação de tempo para a realização dessa etapa. Com as sugestões originadas nos grupos focais, foi elaborada a versão final do questionário.

\section{RESULTADOS}

Os artigos encontrados durante a equivalência conceitual e de itens mostraram que o STD-KQ é utilizado para avaliar o conhecimento de diversos grupos. São exemplos estudos realizados com usuários de drogas ${ }^{32}$, com homens que fazem sexo com homens ${ }^{9}$, com adolescentes ${ }^{33}$, em ensaios clínicos ${ }^{34}$, em estudos baseados em teorias comportamentais ${ }^{35}$ e com estudantes universitários ${ }^{36}$.

No âmbito da equivalência semântica, foi constatada uma equidade satisfatória entre as retraduções e o instrumento original. Em sete itens, a versão de consenso não contemplou a T1 nem T2, elaborando-se uma terceira versão para esses itens visando à melhor compreensão. Um exemplo foi na questão 7, em que as expressões "Logo após se infectar com o HIV", presente na T1, e "Após a infecção com HIV", presente na T2, foram substituídas pela expressão "Logo após pegar o HIV". Da mesma forma, na questão 13, em que os dois tradutores traduziram a palavra condom como "preservativo", na versão consenso essa palavra foi substituída por "camisinha", que é um termo mais conhecido e propagado. Outro exemplo foi na questão 26, em que a expressão can protect na T1 e T2 foi traduzida como "pode se proteger", mas na versão de consenso, optou-se por utilizar a expressão "pode evitar", que, apesar de não ter aparecido nas traduções, é uma expressão mais coloquial. Nas questões 9, 10, 21 e 23, também ocorreram adaptações a fim de melhorar a compreensão (Quadro 1).

Os autores deste estudo decidiram, durante a equivalência operacional, manter a forma de administração do questionário original. A versão adaptada para o Brasil pode ser aplicada individualmente para pacientes em ambulatórios e para estudantes de forma coletiva no ambiente escolar. As alternativas das respostas (verdadeiro, falso e não sei) também não foram alteradas. $\mathrm{O}$ enunciado do questionário foi traduzido e complementado com as seguintes frases: "Este questionário é sigiloso, você não será identificado. Por isso, contamos com a sua sinceridade. As suas respostas nos ajudarão a compreender melhor os problemas das doenças sexualmente transmissíveis. Todas as questões são importantes, portanto, evite deixá-las em branco. Para cada questão, por favor faça um círculo em verdadeiro (v), falso (f) ou não sei (ns). Caso você não saiba a resposta, não se preocupe e, por favor, assinale a opção 'não sei'".

Em relação à validade aparente, quatro itens apesentaram valor menor que 70\%. Os CVCt foram superiores ao ponto de corte para os critérios clareza de linguagem (CVCt $=0,89)$, pertinência prática $(C V C t=0,91)$, relevância teórica (CVCt $=0,92)$, amplitude (CVCt $=0,86)$ e equilíbrio (CVCt $=$ 0,86). Apenas o item 13 apresentou baixa evidência de validade, com CVCc $<0,80$ para pertinência prática, e, por isso, foi retirado do instrumento (Quadro 2).

Durante a validação, os juízes constataram a ausência de questões referentes à sífilis no questionário. Assim, dois itens foram elaborados pelo especialista independente e submetidos aos mesmos juízes para análise da validação. O primeiro 
item adicionado (S1) foi "Mesmo que o seu parceiro/parceira não tenha nenhuma lesão no pênis, no ânus ou na vagina, ele/ela pode passar sífilis para você", que apresentou validade aparente $=60 \%$ e CVCc $=0,73$, para o critério de clareza de linguagem, CVCc = 0,93 para pertinência prática e CVCc = 0,93 para relevância teórica. O segundo item (S2) foi "A sífilis pode ficar escondida no corpo por anos", que apresentou validade aparente $=80 \%$ e CVCc $=0,83$ para clareza de linguagem, $C V C c=0,93$ para pertinência prática e CVCc $=0,93$ para relevância teórica.

Os juízes recomendaram a modificação de seis itens (2, $4,6,15,16$ e $\$ 1$ ). Os autores modificaram dois desses itens (itens 2 e 4). O item 2 foi modificado para "Infecções Urinárias Frequentes são causadas pela Clamídia", e as duas versões desse item (a modificada e a não modificada) foram discutidas nos grupos focais. No item 4, foi acrescentada a palavra "também" resultando no item "É mais fácil pegar o HIV se uma pessoa também tiver outra Doença Sexualmente Transmissível (DST)". Nos outros quatro itens, como a discordância ocorreu em cada um deles apenas por um dos seis juízes, optou-se por não modificar esses itens, mantendo a opinião dos outros cinco juízes. O especialista independente considerou apropriadas todas as alterações realizadas, concordando com os itens não modificados.

Quadro 1. Comparação entre os itens originais em inglês e as retraduções do instrumento Questionário sobre Conhecimento de Doenças Sexualmente Transmissíveis (STD-KQ)

\begin{tabular}{|c|c|c|c|c|c|c|}
\hline No. & Original em Inglês & Traduzido 1 (T1) & Retraduzido 1 (R1) & Traduzido 2 (T2) & Retraduzido 2 (R2) & 1a Versão Síntese \\
\hline 1 & $\begin{array}{l}\text { Genital Herpes is caused by } \\
\text { the same virus as HIV }\end{array}$ & $\begin{array}{l}\text { Herpes Genital é causada } \\
\text { pelo mesmo vírus que } \\
\text { o HIV }\end{array}$ & $\begin{array}{l}\text { Genital Herpes is caused by } \\
\text { the same virus that causes } \\
\text { the HIV }\end{array}$ & $\begin{array}{l}\text { Herpes Genital é causado } \\
\text { pelo mesmo vírus do HIV }\end{array}$ & $\begin{array}{l}\text { Genital Herpes is caused by } \\
\text { the same virus of HIV }\end{array}$ & $\begin{array}{l}\text { Herpes Genital é causado } \\
\text { pelo mesmo vírus do HIV }\end{array}$ \\
\hline 2 & $\begin{array}{l}\text { Frequently urinary } \\
\text { infection can cause } \\
\text { Chlamydia }\end{array}$ & $\begin{array}{l}\text { Infecção urinária frequente } \\
\text { pode causar Clamídia }\end{array}$ & $\begin{array}{l}\text { Frequently urinary } \\
\text { infection can cause } \\
\text { Chlamydia }\end{array}$ & $\begin{array}{l}\text { Infecção urinária frequente } \\
\text { pode causar Clamídia }\end{array}$ & $\begin{array}{l}\text { Frequent urinary infection } \\
\text { can cause Chlamydia }\end{array}$ & $\begin{array}{l}\text { Infecção urinária frequente } \\
\text { pode causar Clamídia }\end{array}$ \\
\hline 3 & $\begin{array}{l}\text { There is a cure for } \\
\text { Gonorrhea }\end{array}$ & $\begin{array}{l}\text { Existe uma cura para } \\
\text { Gonorreia }\end{array}$ & $\begin{array}{l}\text { There is a cure for } \\
\text { Gonorrhea }\end{array}$ & $\begin{array}{l}\text { Existe uma cura para } \\
\text { Gonorreia }\end{array}$ & $\begin{array}{l}\text { There is a cure for } \\
\text { Gonorrhea }\end{array}$ & $\begin{array}{l}\text { Existe uma cura para } \\
\text { Gonorreia }\end{array}$ \\
\hline 4 & $\begin{array}{l}\text { It is easier to get HIV if } \\
\text { a person has another } \\
\text { Sexually Transmitted } \\
\text { Disease }\end{array}$ & $\begin{array}{l}\text { É mais fácil pegar o HIV } \\
\text { se uma pessoa tiver outra } \\
\text { Doença Sexualmente } \\
\text { Transmissível }\end{array}$ & $\begin{array}{l}\text { It is easier to get HIV if } \\
\text { a person has another } \\
\text { sexually transmitted } \\
\text { disease }\end{array}$ & $\begin{array}{l}\text { Torna-se mais fácil } \\
\text { contrair HIV se uma } \\
\text { pessoa possuir outras } \\
\text { Doenças Sexualmente } \\
\text { Transmissíveis }\end{array}$ & $\begin{array}{l}\text { It becomes easier to get } \\
\text { HIV if a person has other } \\
\text { Sexually Transmitted } \\
\text { Diseases }\end{array}$ & $\begin{array}{l}\text { É mais fácil pegar o HIV } \\
\text { se uma pessoa tiver outra } \\
\text { Doença Sexualmente } \\
\text { Transmissível (DST) }\end{array}$ \\
\hline 5 & $\begin{array}{l}\text { Human Papillomavirus } \\
\text { (HPV) is caused by the } \\
\text { same virus that causes HIV }\end{array}$ & $\begin{array}{l}\text { O Papilomavírus Humano } \\
\text { (HPV) é causado pelo } \\
\text { mesmo vírus que causa } \\
\text { o HIV }\end{array}$ & $\begin{array}{l}\text { The Human papillomavirus } \\
\text { (HPV) is caused by the } \\
\text { same virus that causes } \\
\text { the HIV }\end{array}$ & $\begin{array}{l}\text { Papilomavírus Humano } \\
\text { (HPV) é causado pelo } \\
\text { mesmo vírus do HIV }\end{array}$ & $\begin{array}{l}\text { Human Papillomavirus } \\
\text { (HPV) is caused by the } \\
\text { HIV virus }\end{array}$ & $\begin{array}{l}\text { O Papilomavírus Humano } \\
\text { (HPV) é causado pelo } \\
\text { mesmo vírus que causa } \\
\text { o HIV }\end{array}$ \\
\hline 6 & $\begin{array}{l}\text { Having anal sex increase } \\
\text { a person's risk of getting } \\
\text { Hepatitis B }\end{array}$ & $\begin{array}{l}\text { Praticar sexo anal aumenta } \\
\text { o risco de uma pessoa } \\
\text { pegar Hepatite B }\end{array}$ & $\begin{array}{l}\text { Having anal sex increase } \\
\text { the risks of a person } \\
\text { getting Hepatitis B }\end{array}$ & $\begin{array}{l}\text { Fazer sexo anal aumenta } \\
\text { o risco de uma pessoa } \\
\text { contrair Hepatite B }\end{array}$ & $\begin{array}{l}\text { Having anal sex increase } \\
\text { the risks of a person } \\
\text { contracting Hepatitis B }\end{array}$ & $\begin{array}{l}\text { Fazer sexo anal aumenta } 0 \\
\text { risco de uma pessoa pegar } \\
\text { Hepatite } B\end{array}$ \\
\hline 7 & $\begin{array}{l}\text { Soon after a infection with } \\
\text { HIV a person develops } \\
\text { open sores on his or her } \\
\text { genital (penis or vagina) }\end{array}$ & $\begin{array}{l}\text { Logo após se infectar } \\
\text { com HIV uma pessoa } \\
\text { desenvolve feridas abertas } \\
\text { nos órgãos genitais (pênis } \\
\text { ou na vagina) }\end{array}$ & $\begin{array}{l}\text { Short after infected with } \\
\text { HIV a person develops } \\
\text { open wounds on the } \\
\text { genital organs (penis or } \\
\text { vagina) }\end{array}$ & $\begin{array}{l}\text { Logo após a infecção com } \\
\text { HIV, a pessoa desenvolve } \\
\text { feridas abertas no seu } \\
\text { genital (pênis ou vagina) }\end{array}$ & $\begin{array}{l}\text { Soon after infection with } \\
\text { HIV, a person develops } \\
\text { open sores in your genital } \\
\text { (penis or vagina) }\end{array}$ & $\begin{array}{l}\text { Logo após pegar o HIV a } \\
\text { pessoa desenvolve feridas } \\
\text { abertas nos órgãos genitais } \\
\text { (pênis ou na vagina) }\end{array}$ \\
\hline 8 & $\begin{array}{l}\text { There is a cure for } \\
\text { Chlamydia }\end{array}$ & $\begin{array}{l}\text { Existe uma cura para } \\
\text { Clamídia }\end{array}$ & $\begin{array}{l}\text { There is a cure for } \\
\text { Chlamydia }\end{array}$ & Existe cura para a Clamídia & $\begin{array}{l}\text { There is a cure for } \\
\text { Chlamydia }\end{array}$ & $\begin{array}{l}\text { Existe uma cura para } \\
\text { Clamídia }\end{array}$ \\
\hline 9 & $\begin{array}{l}\text { A woman who has } \\
\text { Genital Herpes can pass } \\
\text { to infection to her baby } \\
\text { during childbirth }\end{array}$ & $\begin{array}{l}\text { Uma mulher que tem } \\
\text { Herpes Genital pode passar } \\
\text { a infecção ao seu bebê } \\
\text { durante o parto }\end{array}$ & $\begin{array}{l}\text { A woman who has Genital } \\
\text { Herpes can transmit the } \\
\text { infection to her baby } \\
\text { during childbirth }\end{array}$ & $\begin{array}{l}\text { Uma mulher que tenha } \\
\text { Herpes Genital pode passar } \\
\text { a infecção para o recém- } \\
\text {-nascido durante o parto }\end{array}$ & $\begin{array}{l}\text { A woman who has Genital } \\
\text { Herpes can pass to } \\
\text { infection to her newborn } \\
\text { during childbirth }\end{array}$ & $\begin{array}{l}\text { Uma mulher com Herpes } \\
\text { Genital pode passar a } \\
\text { infeção para o bebê } \\
\text { durante o parto }\end{array}$ \\
\hline 10 & $\begin{array}{l}\text { A woman can look her } \\
\text { body and tell if she has } \\
\text { Gonorrhea }\end{array}$ & $\begin{array}{l}\text { Uma mulher pode olhar } \\
\text { para o seu corpo e dizer se } \\
\text { ela tem Gonorreia }\end{array}$ & $\begin{array}{l}\text { A woman can look to her } \\
\text { body and say if she has } \\
\text { Gonorrhea }\end{array}$ & $\begin{array}{l}\text { Uma mulher pode olhar } \\
\text { para seu corpo e afirmar } \\
\text { que possui Gonorreia }\end{array}$ & $\begin{array}{l}\text { A woman can look to her } \\
\text { body and say that it has } \\
\text { Gonorrhea }\end{array}$ & $\begin{array}{l}\text { Uma mulher pode olhar } \\
\text { para o seu corpo e dizer se } \\
\text { tem Gonorreia }\end{array}$ \\
\hline 11 & $\begin{array}{l}\text { The same virus causes all of } \\
\text { the Sexually Transmitted } \\
\text { Diseases }\end{array}$ & $\begin{array}{l}0 \text { mesmo vírus causa todas } \\
\text { as Doenças Sexualmente } \\
\text { Transmissíveis }\end{array}$ & $\begin{array}{l}\text { The same virus causes all of } \\
\text { the Sexually Transmitted } \\
\text { Diseases }\end{array}$ & $\begin{array}{l}0 \text { mesmo vírus causa todas } \\
\text { as Doenças Sexualmente } \\
\text { Transmissíveis }\end{array}$ & $\begin{array}{l}\text { The same virus causes all of } \\
\text { the Sexually Transmitted } \\
\text { Diseases }\end{array}$ & $\begin{array}{l}0 \text { mesmo vírus causa todas } \\
\text { as Doenças Sexualmente } \\
\text { Transmissíveis (DST) }\end{array}$ \\
\hline 12 & $\begin{array}{l}\text { Human Papillomavirus } \\
\text { (HPV) can cause Genital } \\
\text { Warts }\end{array}$ & $\begin{array}{l}\text { O Papilomavírus Humano } \\
\text { (HPV) pode causar } \\
\text { verrugas genitais }\end{array}$ & $\begin{array}{l}\text { Human Papillomavirus } \\
\text { (HPV) can cause Genital } \\
\text { Warts }\end{array}$ & $\begin{array}{l}\text { Papilomavírus Humano } \\
\text { (HPV) pode causar } \\
\text { verrugas genitais }\end{array}$ & $\begin{array}{l}\text { Human Papillomavirus } \\
\text { (HPV) can cause Genital } \\
\text { Warts }\end{array}$ & $\begin{array}{l}0 \text { Papilomavírus Humano } \\
\text { (HPV) pode causar } \\
\text { verrugas genitais }\end{array}$ \\
\hline
\end{tabular}




\begin{tabular}{|c|c|c|c|c|c|c|}
\hline No. & Original em Inglês & Traduzido 1 (T1) & Retraduzido 1 (R1) & Traduzido 2 (T2) & Retraduzido 2 (R2) & 1a Versão Síntese \\
\hline 13 & $\begin{array}{l}\text { Using a natural skin } \\
\text { condom (Lambskin) can } \\
\text { protect a person from } \\
\text { getting HIV }\end{array}$ & $\begin{array}{l}\text { Usar um preservativo } \\
\text { de pele natural (pele de } \\
\text { cordeiro) pode proteger } \\
\text { uma pessoa de pegar HIV }\end{array}$ & $\begin{array}{l}\text { Using a natural skin } \\
\text { condom (Lambskin) can } \\
\text { protect a person from } \\
\text { getting HIV }\end{array}$ & $\begin{array}{l}\text { Usar preservativo de pele } \\
\text { natural (pele de cordeiro) } \\
\text { pode proteger a pessoa de } \\
\text { contrair HIV }\end{array}$ & $\begin{array}{l}\text { Using a natural skin } \\
\text { condom (Lambskin) can } \\
\text { protect a person from } \\
\text { contracting HIV }\end{array}$ & $\begin{array}{l}\text { Usar uma camisinha de } \\
\text { pele natural (pele de } \\
\text { cordeiro) pode proteger } \\
\text { uma pessoa de pegar HIV }\end{array}$ \\
\hline 14 & $\begin{array}{l}\text { Human Papillomavirus } \\
\text { (HPV) can lead to cancer } \\
\text { in women }\end{array}$ & $\begin{array}{l}\text { O Papilomavírus Humano } \\
\text { (HPV) pode causar câncer } \\
\text { nas mulheres }\end{array}$ & $\begin{array}{l}\text { The Human Papillomavirus } \\
\text { (HPV) can cause cancer in } \\
\text { women }\end{array}$ & $\begin{array}{l}\text { Papilomavírus Humano } \\
\text { (HPV) pode levar ao câncer } \\
\text { em mulheres }\end{array}$ & $\begin{array}{l}\text { Human Papillomavirus } \\
\text { (HPV) can lead to cancer } \\
\text { in women }\end{array}$ & $\begin{array}{l}\text { O Papilomavírus Humano } \\
\text { (HPV) pode levar ao câncer } \\
\text { nas mulheres }\end{array}$ \\
\hline 15 & $\begin{array}{l}\text { A man must have vaginal } \\
\text { sex to get Genital Warts }\end{array}$ & $\begin{array}{l}\text { Um homem deve fazer } \\
\text { sexo vaginal para pegar } \\
\text { verrugas genitais }\end{array}$ & $\begin{array}{l}\text { A man needs to have } \\
\text { vaginal sex to get genital } \\
\text { warts }\end{array}$ & $\begin{array}{l}\text { Um homem deve fazer } \\
\text { sexo vaginal para contrair } \\
\text { verrugas genitais }\end{array}$ & $\begin{array}{l}\text { A man must have vaginal } \\
\text { sex to contract Genital } \\
\text { Warts }\end{array}$ & $\begin{array}{l}\text { Um homem deve fazer } \\
\text { sexo vaginal para pegar } \\
\text { verrugas genitais }\end{array}$ \\
\hline 16 & $\begin{array}{l}\text { Sexually transmitted } \\
\text { diseases can lead to health } \\
\text { problems that are usually } \\
\text { more serious for men than } \\
\text { women }\end{array}$ & $\begin{array}{l}\text { As Doenças Sexualmente } \\
\text { Transmissíveis podem } \\
\text { causar problemas de saúde } \\
\text { que geralmente são mais } \\
\text { graves nos homens que nas } \\
\text { mulheres }\end{array}$ & $\begin{array}{l}\text { Sexually transmitted } \\
\text { diseases can cause health } \\
\text { problems that are normally } \\
\text { more dangerous for men } \\
\text { than women }\end{array}$ & $\begin{array}{l}\text { Doenças Sexualmente } \\
\text { Transmissíveis podem } \\
\text { levar a problemas de saúde } \\
\text { que, geralmente, são mais } \\
\text { sérios em homens do que } \\
\text { em mulheres }\end{array}$ & $\begin{array}{l}\text { Sexually transmitted } \\
\text { diseases can lead to health } \\
\text { problems that are usually } \\
\text { more serious for men than } \\
\text { women }\end{array}$ & $\begin{array}{l}\text { As Doenças Sexualmente } \\
\text { Transmissíveis (DST) } \\
\text { podem levar a problemas } \\
\text { de saúde que geralmente } \\
\text { são mais graves nos } \\
\text { homens que nas mulheres }\end{array}$ \\
\hline 17 & $\begin{array}{l}\text { A woman can tell that she } \\
\text { has Chlamydia if she has } \\
\text { a bad smelling odor from } \\
\text { her vagina }\end{array}$ & $\begin{array}{l}\text { Uma mulher pode dizer } \\
\text { que tem Clamídia se um } \\
\text { mau cheiro vier da sua } \\
\text { vagina }\end{array}$ & $\begin{array}{l}\text { A woman can say she has } \\
\text { Chlamydia if she has a bad } \\
\text { smell coming from her } \\
\text { vagina }\end{array}$ & $\begin{array}{l}\text { Uma mulher pode afirmar } \\
\text { que possui Clamídia se } \\
\text { ela tiver mau odor em sua } \\
\text { vagina }\end{array}$ & $\begin{array}{l}\text { A woman can say that she } \\
\text { has Chlamydia if she has a } \\
\text { bad odor from her vagina }\end{array}$ & $\begin{array}{l}\text { Uma mulher pode dizer } \\
\text { que tem Clamídia se um } \\
\text { mau cheiro vier da sua } \\
\text { vagina }\end{array}$ \\
\hline 18 & $\begin{array}{l}\text { If a person tests positive } \\
\text { for HIV the teste can tell } \\
\text { how sick a person will } \\
\text { become }\end{array}$ & $\begin{array}{l}\text { Se uma pessoa tiver um } \\
\text { teste positivo para HIV, } \\
\text { esse teste pode dizer o } \\
\text { quão doente uma pessoa } \\
\text { irá ficar }\end{array}$ & $\begin{array}{l}\text { If someone tests positive } \\
\text { for HIV, this test can say } \\
\text { how sick a person will } \\
\text { become }\end{array}$ & $\begin{array}{l}\text { Se uma pessoa possuir } \\
\text { teste positivo para HIV, } 0 \\
\text { teste poderá dizer como a } \\
\text { doença será na pessoa }\end{array}$ & $\begin{array}{l}\text { If a person has tested } \\
\text { positive for HIV, the test } \\
\text { can tell how the disease } \\
\text { will be in the person }\end{array}$ & $\begin{array}{l}\text { Se uma pessoa tiver um } \\
\text { teste positivo para HIV, } \\
\text { esse teste pode dizer o } \\
\text { quão doente uma pessoa } \\
\text { irá ficar }\end{array}$ \\
\hline 19 & $\begin{array}{l}\text { There is a vaccine available } \\
\text { to prevent a person from } \\
\text { getting Gonorrhea }\end{array}$ & $\begin{array}{l}\text { Existe uma vacina } \\
\text { disponível para prevenir } \\
\text { uma pessoa de pegar } \\
\text { Gonorreia }\end{array}$ & $\begin{array}{l}\text { There is a vaccine available } \\
\text { to prevent a person from } \\
\text { getting Gonorrhea }\end{array}$ & $\begin{array}{l}\text { Existe uma vacina } \\
\text { disponível para prevenir } \\
\text { uma pessoa de contrair } \\
\text { Gonorreia }\end{array}$ & $\begin{array}{l}\text { There is a vaccine available } \\
\text { to prevent a person from } \\
\text { contracting Gonorrhea }\end{array}$ & $\begin{array}{l}\text { Existe uma vacina } \\
\text { disponível para prevenir } \\
\text { uma pessoa de pegar } \\
\text { Gonorreia }\end{array}$ \\
\hline 20 & $\begin{array}{l}\text { A woman can tell by the } \\
\text { way her body feels if she } \\
\text { has a Sexually Transmitted } \\
\text { Disease }\end{array}$ & $\begin{array}{l}\text { Uma mulher pode dizer } \\
\text { pela forma como } 0 \text { seu } \\
\text { corpo se sente se ela tem } \\
\text { uma Doença Sexualmente } \\
\text { Transmissível }\end{array}$ & $\begin{array}{l}\text { A woman can say by the } \\
\text { way her body feels if she } \\
\text { has a Sexually Transmitted } \\
\text { Disease }\end{array}$ & $\begin{array}{l}\text { Uma mulher pode afirmar } \\
\text { que pela forma como ela } \\
\text { sente seu corpo, ela possui } \\
\text { uma Doença Sexualmente } \\
\text { Transmissível }\end{array}$ & $\begin{array}{l}\text { A woman can tell by the } \\
\text { way her body feels if she } \\
\text { has a Sexually Transmitted } \\
\text { Disease }\end{array}$ & $\begin{array}{l}\text { Uma mulher pode dizer } \\
\text { pela forma como sente } \\
\text { o seu corpo se tem uma } \\
\text { Doença Sexualmente } \\
\text { Transmissível (DST) }\end{array}$ \\
\hline 21 & $\begin{array}{l}\text { A person who has Genital } \\
\text { Herpes must have open } \\
\text { sores to give the infection } \\
\text { to his/her sexual partner }\end{array}$ & $\begin{array}{l}\text { Uma pessoa que tem } \\
\text { Herpes Genital deve ter } \\
\text { feriadas abertas para } \\
\text { transmitir a infecção para } \\
\text { o seu parceiro ou parceira } \\
\text { sexual }\end{array}$ & $\begin{array}{l}\text { A person who has Genital } \\
\text { Herpes must have open } \\
\text { wounds to transmit the } \\
\text { infection to his/her sexual } \\
\text { partner }\end{array}$ & $\begin{array}{l}\text { Uma pessoa que possui } \\
\text { Herpes Genital precisa ter } \\
\text { feridas abertas para que } \\
\text { seja transmitida a infecção } \\
\text { para seu parceiro sexual }\end{array}$ & $\begin{array}{l}\text { A person who has Genital } \\
\text { Herpes must to have open } \\
\text { wounds to be transmitted } \\
\text { the infection to their } \\
\text { sexual partner }\end{array}$ & $\begin{array}{l}\text { Uma pessoa com Herpes } \\
\text { Genital deve ter feridas } \\
\text { abertas para passar } \\
\text { a infecção para o seu } \\
\text { parceiro ou parceira sexual }\end{array}$ \\
\hline 22 & $\begin{array}{l}\text { There is a vaccine that } \\
\text { prevents a person from } \\
\text { getting Chlamydia }\end{array}$ & $\begin{array}{l}\text { Existe uma vacina que } \\
\text { previne uma pessoa de } \\
\text { pegar Clamídia }\end{array}$ & $\begin{array}{l}\text { There is a vaccine that } \\
\text { prevents a person from } \\
\text { getting Chlamydia }\end{array}$ & $\begin{array}{l}\text { Existe uma vacina que } \\
\text { previne uma pessoa de } \\
\text { contrair Clamídia }\end{array}$ & $\begin{array}{l}\text { There is a vaccine that } \\
\text { prevents a person from } \\
\text { contracting Chlamydia }\end{array}$ & $\begin{array}{l}\text { Existe uma vacina que } \\
\text { previne uma pessoa de } \\
\text { pegar Clamídia }\end{array}$ \\
\hline 23 & $\begin{array}{l}\text { A man can tell by the way } \\
\text { his body feels if he has } \\
\text { Hepatitis B }\end{array}$ & $\begin{array}{l}\text { Um homem pode dizer pela } \\
\text { forma como o seu corpo se } \\
\text { sente se tem Hepatite B }\end{array}$ & $\begin{array}{l}\text { A man can say by the way } \\
\text { his body feels if he has } \\
\text { Hepatitis B }\end{array}$ & $\begin{array}{l}\text { Um homem pode afirmar } \\
\text { que pela forma como ele } \\
\text { sente seu corpo, ele possui } \\
\text { Hepatite B }\end{array}$ & $\begin{array}{l}\text { A man can say by the way } \\
\text { his body feels if he has } \\
\text { Hepatitis B }\end{array}$ & $\begin{array}{l}\text { Um homem pode dizer pela } \\
\text { forma como sente } 0 \text { seu } \\
\text { corpo se tem Hepatite } B\end{array}$ \\
\hline 24 & $\begin{array}{l}\text { If a person had Gonorrhea } \\
\text { in the past he or she is } \\
\text { immune (protected) from } \\
\text { getting it again }\end{array}$ & $\begin{array}{l}\text { Se uma pessoa teve } \\
\text { Gonorreia no passado ele } \\
\text { ou ela é imune (protegido) } \\
\text { e não pode pegar de novo }\end{array}$ & $\begin{array}{l}\text { If a person had Gonorrhea } \\
\text { in the past he or she is } \\
\text { immune (protected) and } \\
\text { cannot get it again }\end{array}$ & $\begin{array}{l}\text { Se uma pessoa teve } \\
\text { Gonorreia no passado, ela } \\
\text { é imune (protegido) de } \\
\text { contrair novamente }\end{array}$ & $\begin{array}{l}\text { If a person had Gonorrhea } \\
\text { in the past he or she is } \\
\text { immune (protected) from } \\
\text { contracting it again }\end{array}$ & $\begin{array}{l}\text { Se uma pessoa teve } \\
\text { Gonorreia no passado, ela } \\
\text { é imune (protegido) e não } \\
\text { pode pegar de novo }\end{array}$ \\
\hline 25 & $\begin{array}{l}\text { Human Papillomavirus } \\
\text { (HPV) can cause HIV }\end{array}$ & $\begin{array}{l}\text { O Papilomavírus Humano } \\
\text { (HPV) pode causar o HIV }\end{array}$ & $\begin{array}{l}\text { The Human Papillomavirus } \\
\text { (HPV) can cause HIV }\end{array}$ & $\begin{array}{l}\text { Papilomavírus Humano } \\
\text { (HPV) pode causar HIV }\end{array}$ & $\begin{array}{l}\text { Human Papillomavirus } \\
\text { (HPV) can cause HIV }\end{array}$ & $\begin{array}{l}\text { O Papilomavírus Humano } \\
\text { (HPV) pode causar o HIV }\end{array}$ \\
\hline 26 & $\begin{array}{l}\text { A man can protect himself } \\
\text { from getting Genital Warts } \\
\text { by washing his genitals } \\
\text { after sex }\end{array}$ & $\begin{array}{l}\text { Um homem pode se } \\
\text { proteger de pegar Verrugas } \\
\text { Genitais lavando seu órgão } \\
\text { genital após o sexo }\end{array}$ & $\begin{array}{l}\text { A man can protect himself } \\
\text { from getting Genital Warts } \\
\text { by washing his genitals } \\
\text { after sex }\end{array}$ & $\begin{array}{l}\text { Um homem pode se } \\
\text { proteger de contrair } \\
\text { Verrugas Genitais lavando } \\
\text { seus genitais após o sexo }\end{array}$ & $\begin{array}{l}\text { A man can protect himself } \\
\text { from contracting Genital } \\
\text { Warts by washing his } \\
\text { genitals after sex }\end{array}$ & $\begin{array}{l}\text { Um homem pode evitar de } \\
\text { pegar Verrugas Genitais } \\
\text { lavando seus genitais após } \\
\text { o sexo }\end{array}$ \\
\hline 27 & $\begin{array}{l}\text { There is a vaccine that } \\
\text { can protect a person from } \\
\text { getting Hepatitis } B\end{array}$ & $\begin{array}{l}\text { Existe uma vacina que } \\
\text { pode proteger uma pessoa } \\
\text { de pegar Hepatite B }\end{array}$ & $\begin{array}{l}\text { There is a vaccine that } \\
\text { can protect a person from } \\
\text { getting Hepatitis } B\end{array}$ & $\begin{array}{l}\text { Existe uma vacina que } \\
\text { protege uma pessoa de } \\
\text { contrair Hepatite B }\end{array}$ & $\begin{array}{l}\text { There is a vaccine that } \\
\text { protect a person from } \\
\text { contracting Hepatitis B }\end{array}$ & $\begin{array}{l}\text { Existe uma vacina que } \\
\text { pode proteger uma pessoa } \\
\text { de pegar Hepatite B }\end{array}$ \\
\hline
\end{tabular}


Quadro 2. Validade aparente e cálculo do Coeficiente de Validade de Conteúdo

\begin{tabular}{|c|c|c|c|c|}
\hline \multirow{2}{*}{ Item } & \multirow{2}{*}{ VA } & \multicolumn{3}{|c|}{ CVCC } \\
\hline & & $\mathrm{Cl}$ & PP & RT \\
\hline 1. Herpes Genital é causada pelo mesmo vírus do HIV & $100 \%$ & 0,96 & 0,83 & 0,96 \\
\hline 2. Infecção Urinária frequente pode causar Clamídia & $60 \%$ & 0,80 & 0,96 & 0,90 \\
\hline 3. Existe uma cura para Gonorreia & $100 \%$ & 0,93 & 0,83 & 0,96 \\
\hline 4. É mais fácil pegar o HIV se uma pessoa tiver outra Doença Sexualmente Transmissível (DST) & $60 \%$ & 0,86 & 0,96 & 0,96 \\
\hline 5. 0 Papilomavírus Humano (HPV) é causado pelo mesmo vírus que causa o HIV & $100 \%$ & 0,96 & 0,90 & 0,86 \\
\hline 6. Fazer sexo anal aumenta o risco de uma pessoa pegar Hepatite B & $60 \%$ & 0,90 & 0,90 & 0,90 \\
\hline 7. Logo após pegar o HIV a pessoa desenvolve feridas abertas nos órgãos genitais (pênis ou na vagina) & $80 \%$ & 0,93 & 0,93 & 0,93 \\
\hline 8. Existe uma cura para Clamídia & $100 \%$ & 0,93 & 0,96 & 0,96 \\
\hline 9. Uma mulher com Herpes Genital pode passar a infecção para o bebê durante o parto & $80 \%$ & 0,93 & 0,96 & 0,96 \\
\hline 10. Uma mulher pode olhar para o seu corpo e dizer se tem Gonorreia & $100 \%$ & 0,93 & 0,86 & 0,86 \\
\hline 11. 0 mesmo vírus causa todas as Doenças Sexualmente Transmissíveis (DST) & $100 \%$ & 0,93 & 0,96 & 0,93 \\
\hline 12. 0 Papilomavírus Humano (HPV) pode causar verrugas genitais & $100 \%$ & 0,93 & 0,96 & 0,96 \\
\hline 13. Usar uma camisinha de pele natural (pele de cordeiro) pode proteger uma pessoa de pegar HIV & $50 \%$ & 0,86 & 0,73 & 0,86 \\
\hline 14. 0 Papilomavírus Humano (HPV) pode levar ao câncer nas mulheres & $80 \%$ & 0,90 & 0,93 & 0,96 \\
\hline 15. Um homem deve fazer sexo vaginal para pegar verrugas genitais & $80 \%$ & 0,76 & 0,96 & 0,96 \\
\hline $\begin{array}{l}\text { 16. As Doenças Sexualmente Transmissíveis (DST) podem levar a problemas de saúde que geralmente são mais graves nos } \\
\text { homens que nas mulheres }\end{array}$ & $80 \%$ & 0,73 & 0,86 & 0,86 \\
\hline 17. Uma mulher pode dizer que tem Clamídia se um mau cheiro vier da sua vagina & $100 \%$ & 0,86 & 0,93 & 0,90 \\
\hline 18. Se uma pessoa tiver um teste positivo para HIV, esse teste pode dizer o quão doente uma pessoa irá ficar & $80 \%$ & 0,93 & 0,86 & 0,93 \\
\hline 19. Existe uma vacina disponível para prevenir uma pessoa de pegar Gonorreia & $100 \%$ & 0,93 & 0,90 & 0,90 \\
\hline 20. Uma mulher pode dizer pela forma como sente o seu corpo se tem uma Doença Sexualmente Transmissível (DST) & $100 \%$ & 0,90 & 0,96 & 0,96 \\
\hline 21. Uma pessoa com Herpes Genital deve ter feridas abertas para passar a infecção para o seu parceiro ou parceira sexual & $100 \%$ & 0,90 & 0,93 & 0,93 \\
\hline 22. Existe uma vacina que previne uma pessoa de pegar Clamídia & $100 \%$ & 0,90 & 0,86 & 0,86 \\
\hline 23. Um homem pode dizer pela forma como sente o seu corpo se tem Hepatite B & $80 \%$ & 0,86 & 0,86 & 0,90 \\
\hline 24. Se uma pessoa teve Gonorreia no passado, ela é imune (protegido) e não pode pegar de novo & $80 \%$ & 0,86 & 0,93 & 0,93 \\
\hline 25. 0 Papilomavírus Humano (HPV) pode causar o HIV & $80 \%$ & 0,86 & 0,86 & 0,93 \\
\hline 26. Um homem pode evitar de pegar Verrugas Genitais lavando seus genitais após o sexo & $100 \%$ & 0,93 & 0,93 & 0,93 \\
\hline 27. Existe uma vacina que pode proteger uma pessoa de pegar Hepatite $B$ & $100 \%$ & 0,93 & 0,96 & 0,96 \\
\hline Coeficiente de Validade de Conteúdo Total (CVCt) & & 0,89 & 0,91 & 0,92 \\
\hline
\end{tabular}

VA: validade aparente; CVCc: Coeficiente de Validade de Conteúdo do item; CL: clareza de linguagem; PP: pertinência prática; RT: relevância teórica; CVCt: Coeficiente de Validade de Conteúdo total do questionário.

Quanto à dimensão teórica, o coeficiente Kappa foi de 0,61 , com p-valor geral <0,001 e intervalo de confiança de $95 \%$, variando de 0,53 a 0,69 . Esse valor representa concordância substancial entre os juízes ${ }^{29}$.

Em relação aos grupos focais dos universitários, a média de idade foi de 20,6 anos ( $D P=2,3$ anos), variando entre $18 \mathrm{e}$ 24 anos. Todos eram solteiros, 8 (53,3\%) eram do sexo feminino e 12 (80\%) se autodeclararam brancos. Em relação ao curso, 5 (33,3\%) eram do curso de Direito, 4 (26,7\%) eram do curso de Letras-Inglês, 2 (13,3\%) eram do curso de Pedagogia, 2 (13,3\%) eram do curso de Engenharia de Alimentos, 1 (6,7\%) era do curso de Enfermagem e 1 (6,7\%) era do curso de Química-Licenciatura. A idade média dos usuários dos centros comunitários foi de 36,2 anos (DP = 13,8 anos), variando entre 18 e 64 anos. Oito participantes (53,3\%) eram do sexo feminino, $7(46,6 \%)$ se autodeclararam pardos e $9(60,0 \%)$ eram casados ou conviviam com um companheiro. Em relação à escolaridade, a maioria possuía o ensino fundamental incompleto ou o ensino superior incompleto ( $26,6 \%$ cada).

O tempo médio de duração dos grupos focais foi de 11,6 minutos ( $D P=2,15$ minutos) para os estudantes universitários e 17,6 minutos ( $D P=2,05$ minutos) para os usuários dos centros comunitários. No que concerne ao enunciado do questionário, todos os participantes declararam que era compreensível. Em relação ao item 2, 80\% dos estudantes e $60 \%$ dos usuários afirmaram que a frase "Infecções Urinárias Frequentes são causadas pela Clamídia" era a mais apropriada, corroborando a sugestão dos juízes especialistas e do especialista independente. Os dois itens sobre a síflis acrescentados no questionário foram considerados apropriados por todos os estudantes e por $80,0 \%$ dos usuários dos centros comunitários. O item 13, que apresentou baixa valida- 
ção de conteúdo, foi discutido com os participantes, os quais concordaram com os juízes especialistas que a frase não era apropriada para a nossa cultura.

Após a retirada e o acréscimo de itens, os CVCt para cada critério foram recalculados, mantendo o mesmo valor para clareza de linguagem $(\mathrm{CVCt}=0,89)$ e aumentando em 0,1 para pertinência prática $(\mathrm{CVCt}=0,92)$ e para relevância teórica $(C V C t=0,93)$. Com as recomendações dos grupos focais e o acréscimo de itens, foi elaborada a versão final do questionário (Quadro 3).

\section{DISCUSSÃO}

O presente estudo objetivou adaptar o STD-QK para a cultura brasileira. O fato de as DST serem um problema de saúde pública brasileira' ressalta a necessidade do investimento de novas pesquisas pela comunidade científica. Até a realização do presente estudo, não existiam publicações sobre instrumentos validados para essa finalidade.

A verificação do vocábulo para o contexto em que ele será inserido é uma etapa importante durante a adaptação

Quadro 3. Versão final da adaptação para o português do Brasil do Questionário sobre Conhecimento de Doenças Sexualmente Transmissíveis (STD-KQ)

\begin{tabular}{|c|c|c|c|c|}
\hline Item & Verdadeiro & Falso & NăoSei & Resposta \\
\hline 1. Herpes Genital é causado pelo mesmo vírus do HIV & V & $\mathrm{F}$ & NS & FALSO \\
\hline 2. Infecções Urinárias Frequentes são causadas pela Clamídia & V & $\mathrm{F}$ & NS & VERDADEIRO \\
\hline 3. Existe cura para Gonorreia & V & $\mathrm{F}$ & NS & VERDADEIRO \\
\hline $\begin{array}{l}\text { 4. É mais fácil pegar o HIV se uma pessoa também tiver outra Doença Sexualmente } \\
\text { Transmissível (DST) }\end{array}$ & V & $\mathrm{F}$ & NS & VERDADEIRO \\
\hline 5. 0 Papilomavírus Humano (HPV) é causado pelo mesmo vírus que causa o HIV & V & $\mathrm{F}$ & NS & FALSO \\
\hline 6. Fazer sexo anal aumenta o risco de uma pessoa pegar Hepatite B & V & $\mathrm{F}$ & NS & VERDADEIRO \\
\hline $\begin{array}{l}\text { 7. Logo após pegar o HIV a pessoa desenvolve feridas abertas nos órgãos genitais } \\
\text { (pênis ou na vagina) }\end{array}$ & V & $\mathrm{F}$ & NS & FALSO \\
\hline 8. Existe cura para Clamídia & V & $\mathrm{F}$ & NS & VERDADEIRO \\
\hline $\begin{array}{l}\text { 9. Uma mulher com Herpes Genital pode passar a infecção para } 0 \text { bebê durante } 0 \\
\text { parto }\end{array}$ & V & $\mathrm{F}$ & NS & VERDADEIRO \\
\hline 10. Uma mulher pode olhar para o seu corpo e dizer se tem Gonorreia & V & $\mathrm{F}$ & NS & FALSO \\
\hline 11. Um mesmo vírus causa todas as Doenças Sexualmente Transmissíveis (DST) & V & $\mathrm{F}$ & NS & FALSO \\
\hline 12. 0 Papilomavírus Humano (HPV) pode causar verrugas genitais & V & $\mathrm{F}$ & NS & VERDADEIRO \\
\hline 13. 0 Papilomavírus Humano (HPV) pode levar ao câncer nas mulheres & V & $\mathrm{F}$ & NS & VERDADEIRO \\
\hline 14. Um homem só pega verrugas genitais fazendo sexo vaginal & V & $\mathrm{F}$ & NS & FALSO \\
\hline $\begin{array}{l}\text { 15. As Doenças Sexualmente Transmissíveis (DST) podem levar a problemas de } \\
\text { saúde, que geralmente são mais graves nos homens que nas mulheres }\end{array}$ & V & $\mathrm{F}$ & NS & FALSO \\
\hline 16. Uma mulher pode dizer que tem Clamídia se um mau cheiro vier da sua vagina & V & $\mathrm{F}$ & NS & FALSO \\
\hline $\begin{array}{l}\text { 17. Se uma pessoa tiver um teste positivo para HIV, esse teste pode dizer o quão } \\
\text { doente uma pessoa irá ficar }\end{array}$ & V & $\mathrm{F}$ & NS & FALSO \\
\hline 18. Existe uma vacina disponível para prevenir uma pessoa de pegar Gonorreia & V & $\mathrm{F}$ & NS & FALSO \\
\hline $\begin{array}{l}\text { 19. Uma mulher pode dizer, pela forma como sente o seu corpo, se tem uma Doença } \\
\text { Sexualmente Transmissível (DST) }\end{array}$ & V & $\mathrm{F}$ & NS & FALSO \\
\hline $\begin{array}{l}\text { 20. Uma pessoa com Herpes Genital deve ter feriadas abertas para passar a infecção } \\
\text { para o seu parceiro ou a sua parceira sexual }\end{array}$ & V & $\mathrm{F}$ & NS & FALSO \\
\hline 21. Existe uma vacina que previne uma pessoa de pegar Clamídia & V & $\mathrm{F}$ & NS & FALSO \\
\hline 22. Um homem pode dizer, pela forma como sente o seu corpo, se tem Hepatite B & V & $\mathrm{F}$ & NS & FALSO \\
\hline $\begin{array}{l}\text { 23. Se uma pessoa teve Gonorreia no passado, ela é imune (protegida) e não pode } \\
\text { pegar de novo }\end{array}$ & V & $\mathrm{F}$ & NS & FALSO \\
\hline 24. 0 Papilomavírus Humano (HPV) pode causar o HIV & V & $\mathrm{F}$ & NS & FALSO \\
\hline $\begin{array}{l}\text { 25. Um homem pode evitar de pegar Verrugas Genitais lavando seus genitais após } \\
0 \text { sexo }\end{array}$ & V & $\mathrm{F}$ & NS & FALSO \\
\hline 26. Existe uma vacina que pode proteger uma pessoa de pegar Hepatite $B$ & V & $\mathrm{F}$ & NS & VERDADEIRO \\
\hline $\begin{array}{l}\text { 27. Mesmo que o seu parceiro/parceira não tenha nenhuma lesão no pênis, ou no } \\
\text { ânus ou na vagina, ele/ela pode passar síflis para você }\end{array}$ & V & $\mathrm{F}$ & NS & VERDADEIRO \\
\hline 28. A sífilis pode ficar escondida no corpo por anos & V & $\mathrm{F}$ & NS & VERDADEIRO \\
\hline
\end{tabular}


transcultural ${ }^{37}$. O uso de grupos focais origina sugestões pertinentes que facilitam o entendimento do instrumento ${ }^{37}$. Essa técnica permite o refinamento dos iten ${ }^{31}$, garantindo a compreensão do instrumento por populações com características demográficas diferentes. A versão proposta apresentou equivalência semântica com o instrumento original, além de níveis aceitáveis de validade aparente e de conteúdo.

A retirada e o acréscimo de itens pelo comitê de especialistas podem ser realizados durante a adaptação transcultura ${ }^{38}$. Isso ocorreu na adaptação do instrumento HIV Knowledge Questionnaire para a Malásia ${ }^{39}$ e para a Nigéria ${ }^{40}$, onde teve $\mathrm{o}$ acréscimo e a retirada de itens, respectivamente. As perguntas acrescentadas no questionário da Malásia são únicas e envolvem religião e política, refletindo a realidade desse país. O fato de a versão brasileira do STD-KQ apresentar uma questão a mais do que a original não prejudicará substancialmente a comparabilidade dessa versão com o instrumento original e com os instrumentos validados para outras culturas, visto que o resultado é apresentado na forma de frequências absolutas (escore) e de frequências relativas

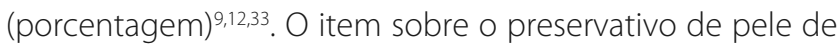
cordeiro foi retirado do estudo, por estar fora do contexto cultural brasileiro. Todos os juízes, o especialista independente e todos os autores concordaram que sua retirada não afetará a avaliação do conhecimento. Isso foi corroborado pelos participantes dos grupos focais. Em relação à literatura, os artigos brasileiros que mencionam os preservativos desse material são de mais de 15 anos atrás ${ }^{41,42}$ e apenas apresentam dados sobre esse material para demonstrar a evolução da produção dos preservativos. É importante salientar que os instrumentos, além de serem culturalmente adequados para determinada população, precisam ser adequados para a vida no dia a dia ${ }^{43}$. A sífilis é a terceira DST mais prevalente no Brasil' e essa prevalência está aumentando nos últimos anos ${ }^{44}$. Dessa forma, para que os dados resultantes desse instrumento sirvam de subsídios para futuras intervenções e políticas públicas, é crucial que sejam incluídos itens sobre a sífilis.

A presente pesquisa apresentou limitações. Ainda que os retradutores sejam profissionais qualificados e proficientes na língua inglesa, o uso de falantes nativos da língua inglesa e reconhecidamente (titulados) e conhecedores do português brasileiro seria mais adequado. Outro aspecto é que o tamanho dos grupos focais foi definido pelos pesquisadores. Como essa etapa da validação envolve uma abordagem qualitativa, essa escolha é justificáve ${ }^{30}$. Outra limitação do estudo é que ele foi realizado em apenas uma cidade do estado do Rio Grande do Sul. No entanto, a fim de garantir que o instrumento seja adequado para todos os brasileiros, evitou-se utilizar expressões regionais, preservando-se apenas palavras compreensíveis para a população em geral. Outro ponto a considerar é que a comparação das frequências absolutas com a versão original e com as adaptações para outros países poderá sofrer limitações.

\section{CONCLUSÃO}

O processo inicial da adaptação transcultural desse questionário apresentou resultados satisfatórios. Algumas adversidades observadas a respeito da compreensão dos itens foram adequadamente retificadas. A concordância substancial entre os juízes em relação à dimensão teórica é uma ferramenta que auxiliará na previsão e compreensão da análise fatorial, sendo a real dimensão teórica de cada item confirmada por meio dessa técnica. Dessa forma, esse questionário parece adequado para a realização de futuras investigações sobre a validade de constructo e a fidedignidade, as quais posteriormente permitirão obter evidências sobre a aplicabilidade desse questionário para avaliação do conhecimento.

\section{CONTRIBUIÇÕES INDIVIDUAIS}

Lisiane Ortiz Teixeira - Participou do desenvolvimento teórico-metodológico; realizou a coleta, análise e processamento dos dados; participou da elaboração do artigo e aprovou a versão final.

Vera Lúcia Marques Figueiredo - Participou do desenvolvimento teórico-metodológico; colaborou substancialmente na redação do manuscrito e na revisão crítica do conteúdo intelectual e aprovou a versão final.

Raúl Andrés Mendoza-Sassi - Participou do desenvolvimento teórico-metodológico; conduziu a análise e processamento dos dados, participou da elaboração do artigo e aprovou a versão final.

\section{CONFLITOS DE INTERESSE}

Os autores declaram que não há conflitos de interesse neste estudo.

\section{AGRADECIMENTOS}

Agradecemos aos tradutores, aos retradutores, aos juízes especialistas e ao especialista independente, que possibilitaram o desenvolvimento deste estudo.

Este estudo foi financiado pela Fundação de Amparo à Pesquisa do Estado do Rio Grande do Sul (Fapergs) e pela Universidade Federal do Rio Grande (FURG).

\section{REFERÊNCIAS}

1. Brasil. Portal Brasil. HIV e DST. Disponível em: <http://www.brasil.gov.br/saude/2011/09/ hiv-e-dst-em-mulheres>. Acesso em: 4 abr. 2015.

2. Jaworski BC, Carey MP. Development and psychometric evaluation of a self-administered questionnaire to measure knowledge of sexually transmitted diseases. AIDS Behav. 2007;11(4):557-74. 
3. Osuji A, Pharr JR, Nwokoro U, Ike A, Ali C, Ejiro O, et al. Impact of HIV testing and counseling (HTC) knowledge on HIV prevention practices among traditional birth attendants in Nigeria. Int J Environ Res Public Health. 2015;12(2):1969-82.

4. Ybarra ML, Korchmaros JD, Prescott TL, Birungi R. A Randomized Controlled Trial to Increase HIV Preventive Information, Motivation, and Behavioral Skills in Ugandan Adolescents. Ann Behav Med. 2015;49(3):473-85.

5. Asare M, Sharma M. Establishing Validity and Reliability of a Health Belief Model and Acculturation Scale for Measuring Safe-Sex and Sexual Communication Behaviors Among African Immigrants for Protecting Against HIV/AIDS. J Immigr Refug Stud. 2014;12(3):191-209.

6. Measurement Instrument Database for the Social Sciences (MIDSS). Disponível em: <http://www.midss.org >. Acesso em: 10 ago. 2015.

7. Talbot TJ, Langdon PE. A revised sexual knowledge assessment tool for people with intellectual disabilities: is sexual knowledge related to sexual offending behaviour? J Intellectual Disabil Res. 2006;50:523-31.

8. Brasil. Ministério da Saúde. Cuidados com sexo oral evitam contrair doenças. Disponível em: <http://www.aids.gov.br/noticia/cuidados-com-sexo-oral-evitam-contrair-doencas>. Acesso em: 14 ago. 2015

9. Mimiaga MJ, Reisner SL, Cranston K, Isenberg D, Bright D, Daffin G, et al. Sexual mixing patterns and partner characteristics of black MSM in Massachusetts at increased risk for HIV infection and transmission. J Urban Health. 2009;86(4):602-23.

10. Mimiaga MJ, Reisner SL, Bland S, Skeer M, Cranston K, Isenberg D, et al. Health system and personal barriers resulting in decreased utilization of HIV and STD testing services among at-risk black men who have sex with men in Massachusetts. AIDS Patient Care STDS. 2009;23(10):825-35.

11. Logie CH, Navia D, Rwigema MJ, Tharao W, Este D, Loutfy MR. A group-based HIV and sexually transmitted infections prevention intervention for lesbian, bisexual, queer and other women who have sex with women in Calgary and Toronto, Canada: study protocol for a non-randomised cohort pilot study. BMJ Open. 2014;4(4):1-8. Disponível em: <http://bmjopen.bmj.com/content/4/4/e005190.full.pdf+htm>. Acesso em: 4 abr. 2015 .

12. Pereira $\mathrm{H}, \mathrm{Carmo} \mathrm{A}$. Sexually transmitted diseases: knowledge and perceived prevalence of symptoms in university students. Int STD Res Rev. 2014;2(1): 1-11.

13. Logie CH, Daniel C, Newman PA, Weaver J, Loutfy MR. A psycho-educational HIV/STI prevention intervention for internally displaced women in Leogane, Haiti: results from a non-randomized cohort pilot study. PLoS ONE. 2014;9(2):e89836.

14. Saad A, Rampal L, Sabitu K, AbdulRahman H, Awaisu A, AbuSamah B, et al. Impact of a customized peer-facilitators training program related to sexual health intervention. Int Health. 2012; $4(4): 277-82$.

15. Turner M0. Acculturation, discrimination and religiosity as predictors of sexual experience and sexual knowledge among Haitian-Canadian, Franco-Ontarian and Anglo-Canadian emerging adults [thesis]. Ottawa: University of Ottawa; 2014. Disponivel em: <http:// www.ruor.uottawa.ca/bitstream/10393/31464/1/0lavarria_Turner_Marcela_2014_ thesis.pdf >. Acessado em: 14 ago. 2015.

16. Ribeiro CFS. Duplo padrão sexual e conhecimento das doenças sexualmente transmissíveis nos estudantes africanos em Braga [tese]. Cabo Verde: Universidade do Minho; 2009. Disponível em: <http://www.portaldoconhecimento.gov.cv/bitstream/10961/3563/1/ DISSERTA\%C3\%87\%C3\%830\%20DE\%20MESTRAD0\%20-pdf>. Acesso em: 14 ago. 2015.

17. Cleland J. Illustrative questionnaire for interview-surveys with young people. Asking Young People About Sexual and Reproductive Behaviors. Illustrative Core Instruments. Geneva: World Health Organization; 2001. Disponível em: <http://www.who.int/reproductivehealth/topics/adolescence/questionnaire.pdf >. Acesso em: 14 ago. 2015.

18. Osis MJD, Duarte GA, Sousa MH. Conhecimento e atitude de usuários do SUS sobre o HPV e as vacinas disponíveis no Brasil. Rev Saude Publica. 2014;48(1):123-33.

19. Miranda AE, Ribeiro D, Rezende EF, Pereira GFM, Pinto VM, Saraceni V. Associação de conhecimento sobre DST e grau de escolaridade entre conscritos em alistamento ao Exército Brasileiro. Brasil, 2007. Ciênc Saúde Coletiva. 2013;18(2):489-97.

20. Gonçalves H, González-Chica DA, Menezes IAM, Hallall PC, Araújol CL, Dumith SC. Conhecimento sobre a transmissão de HIV/AIDS entre adolescentes com 11 anos de idade do Sul do Brasil. Rev Bras Epidemiol. 2013;16(2):420-31.

21. Domingues RMSM, Lauria LM, Saraceni V, Leal MC. Manejo da sífilis na gestação: conhecimentos, práticas e atitudes dos profissionais pré-natalistas da rede SUS do município do Rio de Janeiro. Ciênc Saúde Coletiva. 2013;18(5):1341-51.
22. Sippert N, Van der Sand ICP. Conhecimento de estudantes de escolas inseridas no Projeto "Encontro" do Centro de Atendimento ao Adolescente do Município de ljuí, sobre DST/HIV/ AIDS. Rev Contexto Saúde. 2013;4(06):43-62.

23. Carey MP, Schroder KE Development and psychometric evaluation of the brief HIV Knowledge Questionnaire. AIDS Educ Prev. 2002;14(2):172-82.

24. Reichenheim ME, Moraes CL. Operacionalização de adaptação transcultural de instrumentos de aferição usados em epidemiologia. Rev Saúde Pública. 2007;41(4):665-73.

25. Constant HMRM, Figueiró LR, Signor L, Bish NK, Barros HMT, Ferigolo M. Tradução, adaptação transcultural e validação de conteúdo da versão em português do Coping Behaviours Inventory (CBI) para a população brasileira. Cad Saude Publica. 2014;30(10):2049-56.

26. Soares VOV, Santos HFS, Lima MRM, Aburachid LMC, Greco PJ. Validação de protocolo de categorização de metodologias de ensino nos esportes coletivos com base na Iniciação Esportiva Universal - uma escola da bola: exemplo do futebol. Lecturas: Educación Física y Deportes. 2010;15:144. Disponível em: <http://www.efdeportes.com/efd144/metodologias-de-ensino-na-iniciacao-esportiva-universal.htm>. Acesso em: 14 ago. 2015.

27. Alexandre NMC, Coluci MZO. Validade de conteúdo nos processos de construção e adaptação de instrumentos de medidas. Ciênc Saúde Coletiva. 2011;16(7):3061-8.

28. Hernandez-Nieto RA. Contributions to statistical analysis. Merida: Universidad de Los Andes; 2002.

29. Lands JR, Koch GG. The measurement of observer agreement for categorial data. Biometrics. 1977;33(1):159-74.

30. Catré MNC, Ferreira JA, Pessoa T, Pereira M, Canavarro MC, Catré A. 0 domínio SRPB (Spirituality, Religiousness and Personal Beliefs) do WHOQOL: 0 estudo com grupos focais para validação da versão em Português europeu do WHOQOL-SRPB. Análise Psicológica. 2014;32(4):401-17.

31. Carvalho C, Pinheiro MR, Vilar D, Gouveia JP. Questionário de comunicação em educação sexual na escola - versão adolescentes: estudo de validação com jovens portugueses. Saúde Reprodutiva, Sexualidade e Sociedade. 2014;(4):21-32.

32. Malow RM, Dévieux JG, Stein JA, Rosenberg R, Lerner BG, Attonito J, et al. Neurological function, information-motivation-behavioral skills factors, and risk behaviors among HIVpositive alcohol users. AIDS Behav. 2012;16(8):2297-308.

33. Swenson RR, Rizzo CJ, Brown LK, Payne N, DiClemente RJ, Salazar LF, et al. Prevalence and correlates of HIV testing among sexually active African American adolescents in four US cities. Sex Transm Dis. 2009;36(9): 584-91.

34. Carey MP, Senn TE, Vanable PA, Coury-Doniger P, Urban MA. Brief and intensive behavioral interventions to promote sexual risk reduction among STD clinic patients: results from a randomized controlled trial. AIDS Behav. 2010;14(3):504-17.

35. Scott-Sheldon LA, Carey MP, Vanable PA, Senn TE, Coury-Doniger P, Urban M. Predicting condom use among STD clinic patients using the Information-Motivation-Behavioral Skills (IMB) model. J Health Psychol. 2010;5(7):1093-102.

36. Kennedy BL, Roberts ST. Truths and myths that influence the sexual decision-making process among young multiethnic college women. Arch Psychiatr Nurs. 2009;23(5):366-75.

37. Freire MA, Figueiredo VLM, Gomide A, Jansen K, Silva RA, Magalhães PVS, et al. Escala Hamilton: estudo das características psicométricas em uma amostra do sul do Brasil. J Bras Psiquiatr. 2014;63(4):281-9.

38. Ferreira L, Neves AG, Campana MB, Tavares MCGCF. Guia da AAOS/IWH: sugestões para adaptação transcultural de escalas. Aval Psicol. 2014;13(3):457-61.

39. Choy KK, Huo ALK, Lee JER, Sabapathy MG, Jing 0J, Jutti RC. Frequent misconceptions and low-to-moderate knowledge of HIV and AIDS amongst high-school students in Malaysia. ISRN Infect Dis. 2013;2013:1-6.

40. Saad A, Rampal L, Sabitu K, AbdulRahman H, Awaisu A, AbuSamah B, et al. Impact of a customized peer-facilitators training program related to sexual health intervention. Int Health. 2012;4(4):277-82.

41. Gir E, Duarte G, de Carvalho M J. "Condom": sexo e sexualidade. Medicina (Ribeirao Preto). 1996;29(2/3):309-14.

42. Marinho MB. Entre o funcional e o lúdico: a camisinha nas campanhas de prevenção da. Interface (Botucatu). 2000;4(6):97-108.

43. Moreira IC, Bandeira M, Pollo TC, Oliveira MSD. Cross-cultural adaptation to Brazil of Medication Adherence Rating Scale for psychiatric patients. J Bras Psiquiatr. 2014;63(4):273-80.

44. Brasil. Departamento de DST, AIDS e hepatites virais. Síflis. 2012. Disponível em: <http:// www.aids.gov.br/sites/default/files/anexos/page/2012/50770/apresentacao_4_sifilis_capacitacao_dpp_siflis_r_14015.pdf>: Acesso em: 4 abr. 2015. 